\title{
Synthesis of Biodiesel from Waste Cooking Oil
}

\author{
M. Rakib Uddin ${ }^{1, *}$, Kaniz Ferdous ${ }^{1}$, M. Rahim Uddin ${ }^{1}$, Maksudur R. Khan ${ }^{1,2}$, M. A. Islam ${ }^{1}$ \\ ${ }^{1}$ Department of Chemical Engineering and Polymer Science Shah Jalal University of Science and Technology, Sylhet, Bangladesh \\ ${ }^{2}$ Faculty of Chemical and Natural Resources Engineering, University Malaysia Pahang, Gambang, Kuantan, Pahang, Malaysia \\ *Corresponding author: mruddincep@gmail.com
}

Received December 31, 2012; Revised February 25, 2013; Accepted April 11, 2013

\begin{abstract}
In the present study biodiesel was synthesized from Waste Cook Oil (WCO) by three-step method and regressive analyzes of the process was done. The raw oil, containing 1.9wt\% Free Fatty Acid (FFA) and viscosity was $47.6 \mathrm{~mm}^{2} / \mathrm{s}$. WCO was collected from local restaurant of Sylhet city in Bangladesh. Transesterification method gives lower yield than three-step method. In the three-step method, the first step is saponification of the oil followed by acidification to produce FFA and finally esterification of FFA to produce biodiesel. In the saponification reaction, various reaction parameters such as oil to sodium hydroxide molar ratio and reaction time were optimized and the oil to $\mathrm{NaOH}$ molar ratio was $1: 2$, In the esterification reaction, the reaction parameters such as methanol to FFA molar ratio, catalyst concentration and reaction temperature were optimized. Silica gel was used during esterification reaction to adsorb water produced in the reaction. Hence the reaction rate was increased and finally the FFA was reduced to $0.52 \mathrm{wt} \%$. A factorial design was studied for esterification reaction based on yield of biodiesel. Finally various properties of biodiesel such as FFA, viscosity, specific gravity, cetane index, pour point, flash point etc. were measured and compared with biodiesel and petro-diesel standard. The reaction yield was 79\%.
\end{abstract}

Keywords: saponification, acidification, esterification, factorial design, biodiesel

\section{Introduction}

Due to the predicted shortness of conventional fuels and environmental concerns, a search for alternative fuels has gained recent significant attention. As the calorific value of vegetable oils is comparable to that of diesel, they could be used as fuels in compression ignition engines [1]. The diesel engine is widely used to provide the power source on-land transportation vehicles, marine vessels and power plants. However, a diesel engine also emits various forms of pollutants in gaseous, liquid and solid phases to the environment. These pollutants can endanger human health and damage the ecological environment [2].The concern is increasing worldwide for environmental protection and for the conservation of non-renewable natural resources. Fatty acid methyl esters (FAME) show great potential as diesel substitutes, and they are known to be sources of biodiesel [3].

Biodiesel (FAME) is a clean-burning fuel derived from vegetable oils or animal fat and is an advantageous alternative to fossil diesel fuel because of its biodegradability, bio-renewable nature, very low sulfur content and toxicity, low volatility or flammability, good transport and storage properties, higher cetane number, and its salutary atmospheric $\mathrm{CO}_{2}$ balance for production [4]. Treatments that circumvent the significant problems associated with the high viscosity of plant oils when used as engine fuels are its dilution, micro emulsification, pyrolysis, and transesterification with methanol; the latter approach is used most commonly. The glycerin formed during transesterification is also important because of its numerous applications in the food, cosmetic, and pharmaceutical sectors. FAME is not only currently useful as a diesel fuel additive, but it is also marketed as green industrial degreasing solvents; as diluents for pigments, paints, and coatings, and for military engine fuel applications [4].

Currently, more than $95 \%$ of the world biodiesel is produced from edible oil which is easily available on large scale from the agricultural industry. However, continuous and large-scale production of biodiesel from edible oil has recently been a great concern because they compete with food materials - the food versus fuel dispute [5]. There are concerns that biodiesel feedstock may compete with food supply in the long-term. Non-edible plant oil has been found to be promising crude oil for the production of biodiesel. The use of non-edible oil for biodiesel production compared with edible oil is very significant in developing countries because of the tremendous demand of edible oil as food and they are far too expensive to be used as fuel at present $[5,6]$.

In Bangladesh the potentiality of producing oil source is investigated and it is found that the production potential is not too high. As we have a very large population, the edible oil sources cannot be employed for the biodiesel production. Moreover we have extreme limitation of land. So additional land acquiring is also impossible for the production of oil seeds. The oil seed source that can be used for biodiesel production in Bangladesh are WCO, 
mustard oil, sesame oil, coconut oil, peanut oil, linseed oil, castor oil, nahor oil etc. [7].

The high cost of biodiesel is mainly due to the cost of virgin vegetable oil. Therefore, it is not surprising that the biodiesel produced from vegetable oil (for example, pure soybean oil) costs much more than petroleum based diesel. Therefore, it is necessary to explore ways to reduce production costs of biodiesel. In this sense, methods that permit minimizing the costs of the raw material are of special interest. The use of waste frying oil, instead of virgin oil, to produce biodiesel is an effective way to reduce the raw material cost because waste frying oil is estimated to be about half the price of virgin oil [8].

There are different methods for biodiesel preparation like base or acid catalyzed transesterification [9,10], two step method [11] and three-step method [12]. Encinar et. al [13] prepared biodiesel from WCO by base catalyzed transesterification but the reaction yield was too low then two-step method was conducted to increase the reaction yield. Zheng et. al [8] produced biodiesel from WCO by acid catalyzed transesterification but the molar ratio of oil to methanol was 1:74. In this method huge amount methanol required for reaction and additional cost involved for the separation of biodiesel.

In the present study biodiesel was prepared from WCO by three-step method to increase the reaction yield and minimize the methanol molar ratio. Additionally regressive analyzes study was done by the application of factorial design based on viscosity to find out the better reaction conditions.

\section{Materials and Methods}

\subsection{Chemicals}

Methanol (99-100\%), ethanol (99-100\%), sodium hydroxide pellets (96\%), potassium hydroxide pellets (>84\%), phenolphthalein (PH 8.2-9.8), acetone (99\%), diethyl ether , hydrochloric acid (37\%), iodine , sodium iodide, bromine, carbon tetrachloride, glacial acetic acid, potassium dichromate etc. All the chemicals were used as analytical reagent grade.

\subsection{Raw Materials}

Waste cook oil (palm oil and soybean oil) was collected from local restaurants located in Sylhet city in Bangladesh. The oil was filtered and its properties were measured.

\subsection{Preparation of Biodiesel by Three-step Method}

Three-step method consists of Saponification followed by acidification to produce FFA and finally esterification of FFA to produce biodiesel [12].

\subsubsection{Saponification}

For saponification process required amount of WCO was taken in a three necked flask and mixed with different stoichiometric amount of aqueous sodium hydroxide solution. The mixture was heated under reflux with vigorous stirring at temperature of $100^{\circ} \mathrm{C}$ for different time. The reaction was stopped by cooling the reaction volume. Aqueous sodium hydroxide solution was prepared by dissolving required amount of dry sodium hydroxide $(\mathrm{NaOH})$ in $60-90 \mathrm{ml}$ water. The reaction time and different molar ratio of oil to sodium hydroxide solution through saponification process were optimized.

\subsubsection{Acidification}

After saponification, produced sodium soap solution was treated with different stoichiometric amount of concentrated hydrochloric acid at a temperature of 65$70^{\circ} \mathrm{C}$ under reflux with vigorous stirring. After dissolving the soap, the fatty acid contents were separated in separatory funnel. After separation, hot water wash was given for removing mineral acid from the fatty acid. The FFA content was determined by titration method. The different molar ratio of soap to hydrochloric acid was given and the ratio was optimized.

\subsubsection{Esterification of FFA}

When acidification was completed, produced FFA was reacted with different stoichiometric amount of methanol under reflux with vigorous stirring at different temperature, catalyst concentration, different molar ratio of methanol to FFA and different time. All the reaction parameters were optimized. Silica gel was used during esterification reaction to adsorb water produced in esterification reaction.

After preparing the biodiesel from WCO various physico-chemical properties were measured and compared with the standard biodiesel. The yield of biodiesel was calculated by the following equation:

$$
\text { Yield }=\frac{\mathrm{W}(\text { biodiesel })}{\mathrm{W}(\text { Oil })}
$$

where, W(biodiesel) is the weight of produced biodiesel and W(oil) is weight of oil.

\subsection{Analytical Methods for Oiul and Biodiesel}

To determine FFA of sample and biodiesel, $1 \mathrm{~mL}$ of oil and biodiesel were weighed in gm , then dispersed in $5 \mathrm{~mL}$ diethyl-ether solution followed by titration against $0.1 \mathrm{M}$ $\mathrm{KOH}$ by the method described in AOCS Aa 6-38. Saponification value (SV) was determined by method described by Jeffery et al. [14]. To determined S.V. 2gm sample was taken in $50 \mathrm{~mL}$ alcoholic $\mathrm{KOH}$ then heated at $65^{\circ} \mathrm{C}$ with vigorous stirring for $30 \mathrm{~min}$ and titrated against $0.5 \mathrm{M}$ hydrochloric acid [14]. The iodine value (IV) was determined by titrating the sample with $0.01 \mathrm{~N}$ sodium thiosulphate and chemical reagents until the disappearance of blue color. Iodine value was calculated by following equation:

$$
I V=\frac{\left(V_{1}-V_{2}\right) * S * 0.126 * 100}{W}
$$

where, $\mathrm{V}_{1}$ and $\mathrm{V}_{2}$ are the volume of sodium thiosulphate $(\mathrm{mL})$ required for titration with sample and blank titration, $\mathrm{S}$ is the concentration of $\mathrm{Na}_{2} \mathrm{~S}_{2} \mathrm{O}_{3}$ in Normality, $\mathrm{W}$ is the 
weight of oil sample in gm. Physical properties color, moisture content and density of the sample were by the following ASTM D 1500, ASTM D 1744 (Karl fisher method), ASTM D 1480/81 and ASTM D 240. Viscosity, cloud point, pour point were determined by standards ASTM D445 respectively.

\section{Results and Discussion}

\subsection{Characterization of WCO}

The properties of WCO such as viscosity, specific gravity, moisture content, saponification value, pour point, cloud point etc were measured and presented in Table 1.

\subsection{Preparation of FFA from WCO}

FFA was prepared from WCO by saponification followed by acidification. Saponification was done by the method described above. Saponification was done with different stoichiometric amount of $\mathrm{NaOH}$. After saponification and acidification FFA was produced. The results are represent in Figure 1. From Figure 1, it can be seen that, the optimum molar ratio of oil to $\mathrm{NaOH}$ was $1: 2$ and reaction time was $2.0 \mathrm{~h}$.

\begin{tabular}{|c|c|}
\hline \multicolumn{2}{|c|}{ Table 1. properties of WCO } \\
\hline Properties & $\begin{array}{c}\text { Experimental } \\
\text { value }\end{array}$ \\
\hline Physical state & Liquid \\
\hline Color & Deep oily \\
\hline Specific gravity at $25^{\circ} \mathrm{C}$ & 0.902 \\
\hline Kinematic viscosity, $\mathrm{mm}^{2} / \mathrm{s}$ at $40^{\circ} \mathrm{C}$ & 54.53 \\
\hline FFA content (wt\% of oil) & 275.5 \\
\hline Average molecular weight of FFA (gm/mol) & 864.5 \\
\hline Molecular weight of oil (gm/mol) & 238 \\
\hline Saponification value (mg of $\mathrm{KOH} / \mathrm{gm}$ of oil) & 12 \\
\hline Cloud point $\left({ }^{\circ} \mathrm{C}\right)$ & 6 \\
\hline Pour point $\left({ }^{\circ} \mathrm{C}\right)$ & \\
\hline
\end{tabular}

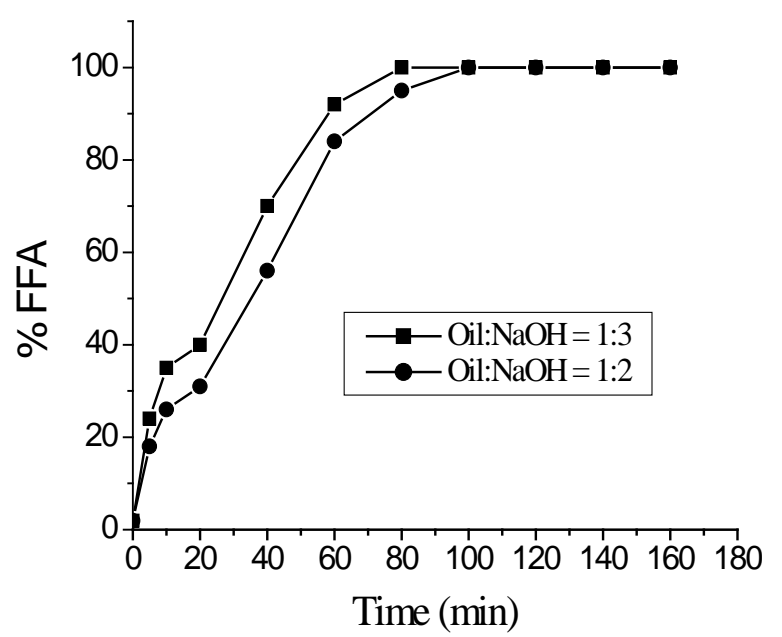

Figure 1. Preparation of FFA from WCO through saponification and acidification

\subsection{Preparation of Biodiesel from FFA}

\subsubsection{Effect of Methanol to FFA Molar Ratio}

The methanol to FFA molar ratio is one of the important parameter that affecting the FFA conversion to biodiesel. The effect of methanol to FFA molar ratio on conversion of FFA was investigated at fixed temperature and catalyst concentration. The results are represented in Figure 2. From the Figure 2, it was found that the FFA conversion to biodiesel was $98 \%$ at $6: 1$ molar ratio of methanol to FFA. Further increase in methanol to FFA molar ratio conversion does not increase. The optimum molar ratio of methanol to FFA was 6:1.

\subsubsection{Effect of Catalyst Concentration on Esterification}

Catalyst concentration has a significant role on conversion of FFA to methyl ester. Increase of catalyst concentration increases the percentage of FFA conversion. At a certain catalyst concentration the conversion was higher. $\mathrm{HCl}$ was used as catalyst. The effect of catalyst concentration on conversion of FFA was investigated the results are represented in Figure 3. From the Figure 3, it can be seen that the conversion was $98 \%$ at the catalyst concentration of $5 \mathrm{wt} \%$ of FFA. Further increasing the catalyst concentration conversion does not increase. The optimum catalyst concentration was $5 \mathrm{wt} \%$ of FFA.

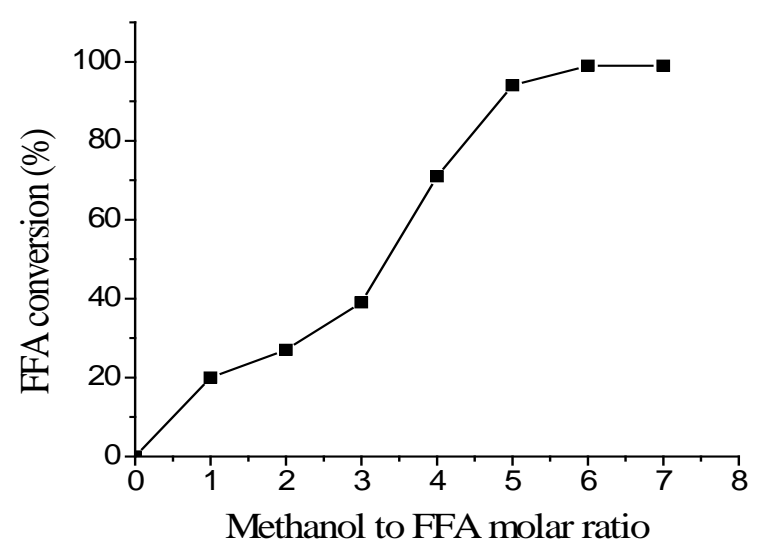

Figure 2. Effect of Methanol to FFA molar ratio on FFA conversion

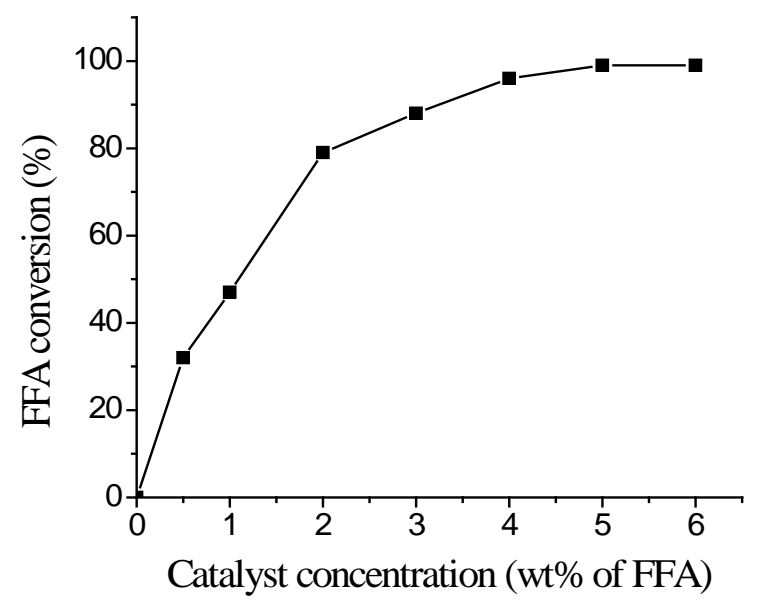


Figure 3. Effect of catalyst concentration on esterification reaction

\subsubsection{Effect of Silica Gel on Esterification Reaction}

Silica gel adsorbs the water produced in esterification reaction. Hence increase the reaction rate. The effect of silica gel was studied in esterification reaction by taking 5 gm silica gel for 50g FFA. Further increasing of silica gel, the conversion remains unchanged. The results are presented in Figure 4. From the Figure 4, it can be seen that more than $99 \%$ conversion in terms of FFA content was achieved within 80 minutes and reaction rate was increased.

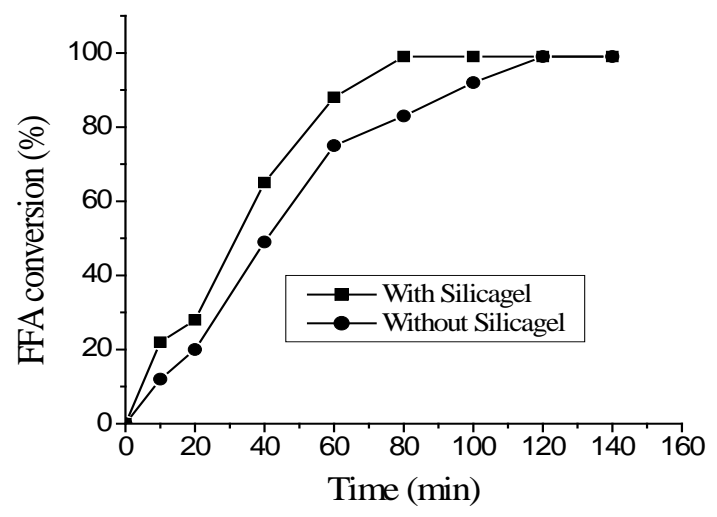

Figure 4. Effect of silica gel in esterification reaction

\subsubsection{Effect of Temperature}

Temperature has a significant effect on conversion of FFA to methyl ester. By increasing temperature \%FFA conversion was increased. At a certain temperature the conversion was higher. The effect temperature on conversion of FFA was investigated the results are represented in Figure 5. From the Figure 5, it can be seen that the conversion was $98 \%$ at $60^{\circ} \mathrm{C}$ temperature. Further increasing of temperature the percentage FFA conversion does not increase. The optimum temperature was $60^{\circ} \mathrm{C}$.

\subsection{Regressive Analyzes of Esterification Reaction}

Four factors (methanol to FFA molar ratio, catalyst concentration, temperature and reaction time) affect the biodiesel production process from WCO. To study the regressive analyzes of Esterification reaction, a factorial design was carried out. The experiments were conducted according to half-Replicate of $2^{4}$ full factorial design. Table 2 shows the decoding values for methanol to FFA molar ratio, catalyst concentration, reaction temperature and reaction time. Eight set of experiments were run for the factorial design and the results are shown in Table 3.

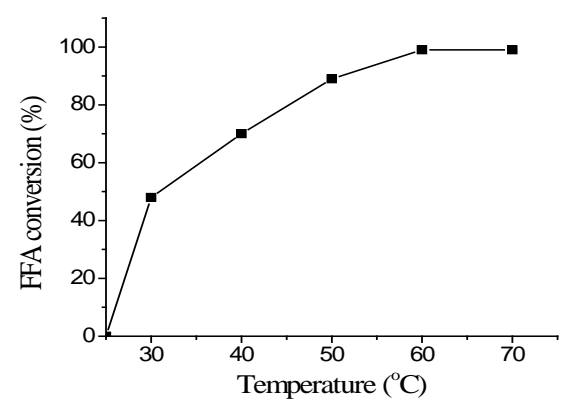

Figure 5. Effect of Temperature on esterification reaction

Table 2. Decoding values of independent variables used in the experimental design

\begin{tabular}{|c|c|c|}
\hline Factors & Max. $(+1)$ & Min. $(-1)$ \\
\hline Molar ratio $\left(\mathrm{X}_{1}\right)$ & 8 & 3 \\
\hline Catalyst conc. $\left(\mathrm{X}_{2}\right)$ & 6 & 2 \\
\hline Temperature, ${ }^{\circ} \mathrm{C}\left(\mathrm{X}_{3}\right)$ & 60 & 40 \\
\hline Time (min) $\left(\mathrm{X}_{4}\right)$ & 90 & 30 \\
\hline
\end{tabular}

Table 3. Design of the experiment using coded value

\begin{tabular}{|c|c|c|c|c|c|c|c|c|c|c|c|c|}
\hline $\begin{array}{c}\text { No. of } \\
\text { runs }\end{array}$ & $\mathrm{X}_{0}$ & $\mathrm{X}_{1}$ & $\mathrm{X}_{2}$ & $\mathrm{X}_{3}$ & $\mathrm{X}_{4}$ & $\mathrm{Y}_{1}$ & $\mathrm{Y}_{2}$ & $\mathrm{Y}_{3}$ & $\mathrm{Y}_{4}$ & $\mathrm{Y}_{5}$ & $\bar{Y}$ & $\mathrm{~S}_{\mathrm{i}}^{2}$ \\
\hline 1 & +1 & +1 & +1 & +1 & +1 & 74 & 76 & 76.8 & 76.5 & 77 & 76.06 & 1.46 \\
\hline 2 & +1 & +1 & +1 & -1 & -1 & 65 & 66 & 64 & 68 & 66.5 & 65.9 & 2.3 \\
\hline 3 & +1 & +1 & -1 & +1 & -1 & 70 & 68 & 69 & 71 & 72 & 70 & 2.5 \\
\hline 4 & +1 & +1 & -1 & -1 & +1 & 72 & 74 & 74.5 & 74 & 74 & 73.7 & 0.95 \\
\hline 5 & +1 & -1 & +1 & +1 & -1 & 68 & 68 & 66.5 & 65 & 65 & 66.5 & 2.25 \\
\hline 6 & +1 & -1 & +1 & -1 & +1 & 74 & 73 & 73 & 75.5 & 72 & 73.5 & 1.75 \\
\hline 7 & +1 & -1 & -1 & +1 & +1 & 70 & 71.5 & 72.2 & 73 & 71 & 71.54 & 1.30 \\
\hline 8 & +1 & -1 & -1 & -1 & -1 & 62 & 60 & 61 & 64 & 64 & 62.2 & 3.2 \\
\hline & & & & & & & & & & & $\sum \bar{Y}=559.4$ & $\sum \mathrm{S}_{\mathrm{i}}^{2}=15.72$ \\
\hline
\end{tabular}

Where $\mathrm{Y}$ is the yield of biodiesel and $\bar{Y}$ is average value of Y. The sample variances were determined and tested for homogeneity on the basis of Cochran's criterion. It was found that the sample variances are homogeneous for the significance level $\alpha=0.05$ and the number of degrees of freedom $v 1=4$ and $v 2=8$ and the error mean square was 1.96 .

Table 4. Sample Variances

\begin{tabular}{|l|c|l|l|}
\hline \multicolumn{4}{|c|}{ Table 4. Sample Variances } \\
\hline $\mathrm{S}_{1}{ }^{2}$ & 1.46 & $\mathrm{~S}_{5}{ }^{2}$ & 2.25 \\
\hline $\mathrm{S}_{2}{ }^{2}$ & 2.3 & $\mathrm{~S}_{6}{ }^{2}$ & 1.75 \\
\hline
\end{tabular}

\begin{tabular}{|c|c|c|c|}
\hline $\mathrm{S}_{3}{ }^{2}$ & 2.5 & $\mathrm{~S}_{7}{ }^{2}$ & 1.30 \\
\hline $\mathrm{S}_{4}{ }^{2}$ & 0.95 & $\mathrm{~S}_{8}{ }^{2}$ & 3.2 \\
\hline
\end{tabular}


The complete regression equation describes the contributions of the various factors on the outcome (response) of the biodiesel conversion.

$$
\begin{aligned}
\widehat{Y}= & b_{o}+b_{1} X_{1}+b_{2} X_{2}+b_{3} X_{3}+b_{4} X_{4} \\
& +b_{12} X_{12}+b_{13} X_{13}+b_{23} X_{23}
\end{aligned}
$$

The coefficients of the regression equation were estimated and the significance of the coefficients was tested using the student T-test. Only three coefficient appeared as insignificant for the significance level $\alpha=$ 0.01 .

Neglecting the insignificant coefficient the final regression equation becomes as:

Using the Fisher's test the adequacy fitness of the regression equation was determined. With $\alpha=0.01, v_{1}=3$ and $v_{2}=32$

$$
\begin{aligned}
\widehat{\mathrm{Y}}= & 69.9+1.49 \mathrm{X}_{1}+1.1 \mathrm{X}_{3} \\
& +3.77 \mathrm{X}_{4}-1.03 \mathrm{X}_{12}
\end{aligned}
$$

the tabulated value of Fisher's $F$ was 4.5 where the experimental value was 3.96. Therefore the equation fits in the experiment.

\subsection{Properties of Biodiesel}

The properties of produced biodiesel such as viscosity, FFA content, moisture content, pour point, cloud point, saponification value, iodine value, specific gravity etc. were presented in Table 5 and compared with standard values. The reaction yield was $79 \%$.

Table 5. Properties of biodiesel produced from WCO by threestepmethod and comparison with standard biodiesel and diesel

\begin{tabular}{|c|c|c|c|}
\hline Properties & $\begin{array}{c}\text { Produced } \\
\text { biodiesel } \\
\text { value }\end{array}$ & $\begin{array}{c}\text { Biodiesel } \\
\text { Standard } \\
{[12,15]}\end{array}$ & $\begin{array}{c}\text { Diesel } \\
\text { standard } \\
{[15]}\end{array}$ \\
\hline $\begin{array}{c}\text { Specific gravity, at } \\
25^{\circ} \mathrm{C}\end{array}$ & 0.792 & $\begin{array}{c}0.88(\text { at } \\
\left.15.5^{\circ} \mathrm{C}\right)\end{array}$ & $\begin{array}{c}0.85(\mathrm{at} \\
\left.15.5^{\circ} \mathrm{C}\right)\end{array}$ \\
\hline $\begin{array}{c}\text { Kinematic viscosity } \\
\left(\mathrm{mm}^{2} / \mathrm{s}\right) \text {, at } 40^{\circ} \mathrm{C}\end{array}$ & 3.29 & $1.9-6.0$ & $1.3-4.1$ \\
\hline FFA content (wt\%) & 0.94 & - & - \\
\hline $\begin{array}{c}\text { Moisture content } \\
(\%)\end{array}$ & 0.12 & $0.05 \% \max$. & 0.161 \\
\hline $\begin{array}{c}\text { Saponification } \\
\text { value }\end{array}$ & 194 & - & - \\
\hline Flash point $\left({ }^{\circ} \mathrm{C}\right)$ & 150 & 100 to 170 & 60 to 80 \\
\hline Iodine value & 88 & - & - \\
\hline Cloud point $\left({ }^{\circ} \mathrm{C}\right)$ & 0 & -3 to 12 & -15 to 5 \\
\hline Pour point $\left({ }^{\circ} \mathrm{C}\right)$ & -3 & -15 to 10 & -35 to -15 \\
\hline Yield $(\%)$ & 79 & - & - \\
\hline
\end{tabular}

\section{Conclusion}

Biodiesel was prepared from WCO by three-step method, in three-step method aqueous sodium hydroxide solution was used for saponification. The optimum molar ratio for saponification by aqueous sodium hydroxide was $1: 2$ oil to $\mathrm{NaOH}$ and reaction time was $2.0 \mathrm{~h}$ at $100^{\circ} \mathrm{C}$. In acidification the molar ratio of soap to hydrochloric acid was 1:2 for sodium soap. In Esterification the optimum molar ratio of methanol to FFA was $6: 1$, the catalyst $(\mathrm{HCl})$ concentration is $5 \mathrm{wt} \%$ of FFA, the reaction temperature was $60^{\circ} \mathrm{C}$ and the reaction time was 2 hour, with silica gel reaction time was reduced to $80 \mathrm{~min}$ and FFA content was reduced to $0.94 \%$. A factorial design was applied to find the optimum conditions for esterification reaction. At optimum conditions $99.06 \%$ conversion of the FFA to FAME was obtained and the viscosity, yield were $3.29 \mathrm{~mm}^{2} / \mathrm{s}$ and $79 \% \mathrm{wt} / \mathrm{wt}$. The properties of produced biodiesel such as viscosity, specific gravity, cloud point, pour point, flash point etc. are nearest to the petro-diesel. The present experimental results support that produced biodiesel from WCO by this method can be successfully used as diesel.

\section{References}

[1] Xie, Wenlei, and Li, Haitao, “Alumina-supported potassium iodide as a heterogeneous catalyst for biodiesel production from soybean oil,” Journal of Molecular Catalysis A: Chemical, 255, 19, May.2006.

[2] Lin, Cherng-Yuan, Lin, Hsiu-An and Hung, Lang-Bang, "Fuel structure and properties of biodiesel produced by the peroxidation process,” Fuel, 85, 1743-1749, 2006.

[3] Liu, Xuejun, He, Huayang, Wang, Yujun and Zhu, Shenlin, "Transesterification of soybean oil to biodiesel using $\mathrm{SrO}$ as a solid base catalyst,” Catalysis Communications, 8, 1107-1111, 2007.

[4] Tanja, Cerce, Siegfried, Peter and Weidner Eckhard. "BiodieselTransesterification of Biological Oils with Liquid Catalysts: Thermodynamic Properties of Oil-Methanol-Amine Mixtures," Industrial \& Engineering Chemistry Research, 40, 9535-9541, 2005.

[5] Mustafa B., "Potential alternatives to edible oils for biodiesel production - a review of current work," Energy Conversion and Management, 52(2), 1479-1492, 2011.

[6] Arjun B.C., Martin, S.T., Suzanne, M.B., Chris, K.W. and Rafiqul, M.I., "Non-edible plant oils as new sources for biodiesel production,” International Journal of Molecular Science, 9(2), 169-180, 2008.

[7] http://www.eoearth.org/article, 2010/04/05.

[8] Zheng, S., Kates, M., Dube, M.A. and McLean, D.D., “Acidcatalyzed production of biodiesel from waste frying oil,” Biomass \& Bioenergy, 30, 267-272, Jan.2006.

[9] Meher, L.C., Sagar,Vidya D.Nnik, S.N., "Technical aspects of biodiesel production by transesterification - a review," Renewable and sustainable Energy Review, 10, 248-268, 2006.

[10] De, B.K. and Bhattacharyya, Biodiesel from minor vegetable oils like karanja oil and nahor oil, Wiley-VCH Verlag GmbH, D-69451 Weinheim, 404-406. 1999.

[11] Zullaikah, Siti, Lai, Chao-Chin, Vali, Shaik, Ramjan and Ju, YiHsu, "A two-step acid-catalyzed process for the production of biodiesel from rice bran oil,” Bioresource Technology, 96, 18891896, 2005.

[12] Morshed, Mahbub, Ferdous, Kaniz, Khan, Maksudur R, Mazumder, M.S.I, Islam, M.A. and Uddin, Md.T., "Rubber seed oil as a potential source for biodiesel production in Bangladesh," Fuel, 90, 2981-2986, Jun.2011.

[13] Encinar, J.M., Gonzalez, J.F. and Rodrıguez-Reinares, Antonio, "Biodiesel from Used Frying Oil.Variables Affecting the Yields and Characteristics of the Biodiesel,” Industrial \& Engineering Chemistry Research, 44, 5491-5499, 2005.

[14] Jeffery, G.H, Bassett, J, Mendham, J. and Denney, R.C., "Vogel’s textbook of quantitative chemical analysis," $5^{\text {th }}$ edition, Longman Scientific and Technical, UK, 308-309. 1991.

[15] Joshi, R.M. and Pegg, M.J. "Flow properties of biodiesel fuel blends at low temperatures,” Fuel, 86, 143-151, 2007. 